BMJ Open

Diabetes

Research

\& Care

\title{
Safety of medical compression stockings in patients with diabetes mellitus or peripheral arterial disease
}

\author{
Ulrich Rother (D) , ${ }^{1}$ Anna Grussler, ${ }^{1}$ Colin Griesbach, ${ }^{2}$ Veronika Almasi-Sperling, \\ Werner Lang, ${ }^{1}$ Alexander Meyer ${ }^{1}$
}

To cite: Rother U, Grussler A, Griesbach C, et al. Safety of medical compression stockings in patients with diabetes mellitus or peripheral arterial disease. BMJ Open Diab Res Care 2020;8:e001316. doi:10.1136/ bmjdrc-2020-001316

- Additional material is published online only. To view please visit the journal online (http://dx.doi.org/10.1136/ bmjdrc-2020-001316).

Received 3 March 2020

Revised 30 April 2020

Accepted 9 May 2020
Check for updates

(C) Author(s) (or their employer(s)) 2020. Re-use permitted under CC BY-NC. No commercial re-use. See rights and permissions. Published by BMJ.

${ }^{1}$ Department of Vascular Surgery, Friedrich-AlexanderUniversitat Erlangen-Nurnberg, Erlangen, Bayern, Germany ${ }^{2}$ Department of Medical Informatics, Biometry and Epidemiology, FriedrichAlexander-Universitat ErlangenNurnberg, Erlangen, Bayern, Germany

Correspondence to Dr Ulrich Rother; ulrich.rother@uk-erlangen.de

\section{ABSTRACT}

Introduction Compression therapy is highly effective in the treatment of many venous diseases, including leg edema. However, its relevance in patients with peripheral arterial disease (PAD) or diabetes mellitus is critically discussed. The aim of the present study was to assess the influence of compression therapy on microperfusion and its safety in patients with PAD or diabetes mellitus. Research design and methods A prospective analysis of 94 consecutive patients (44 patients with diabetes, 45 patients with PAD and 5 healthy controls) undergoing medical compression therapy was performed. Microperfusion was assessed by a combined method of white light tissue spectrometry and laser Doppler flowmetry under medical compression therapy (classes I and II), in different body positions (supine, sitting, standing and elevated position of the leg) and at different locations (great toe, lateral ankle and calf).

Results During the entire study, no compression-related adverse events occurred. Evaluation of microcirculation parameters (oxygen saturation of hemoglobin and flow) at the different locations and in sitting and standing positions (patients with diabetes and PAD) under compression therapy classes I and II revealed no tendency for reduced microperfusion in both groups. In contrast, in the elevated leg position, all mean perfusion values decreased in the PAD and diabetes groups. However, the same effect was seen in the healthy subgroup.

Conclusions In consideration of the present inclusion criteria, use of medical compression stockings is safe and feasible in patients with diabetes or PAD. This study did not find relevant impairment of microperfusion parameters under compression therapy in these patient subgroups in physiologic body positions.

Trial registration number NCT03384758.

\section{INTRODUCTION}

Leg edema is of great importance especially in the aged population, causing general discomfort to the patient as well as malnutrition at the level of microcirculation, resulting in leg ulcers. ${ }^{1}$ One type of therapy for such edemas is the medical diuretic therapy, which however can compromise kidney function in certain patients. $^{2}$ In contrast, medical compression therapy has shown to be highly effective in the treatment as well as in the prevention of leg

\section{Significance of this study}

What is already known about this subject?

- Medical compression therapy has been shown to be highly effective in therapy for leg edema; however, its applicability is critically discussed in patients with diabetes as well as in patients with peripheral arterial disease (PAD).

What are the new findings?

- This study did not find relevant impairment of microperfusion parameters under compression therapy in patients with diabetes mellitus or PAD in physiologic body positions.

- Microperfusion changes under compression therapy in patients with diabetes and PAD were found to be similar to the healthy subgroup.

How might these results change the focus of research or clinical practice?

- Use of medical compression therapy is safe and feasible in patients with diabetes mellitus and PAD.

edema. ${ }^{1}$ However, in patients with peripheral arterial disease (PAD) or diabetes mellitus, both increasing with age, the usage of compression therapy is critically discussed. ${ }^{134}$ In patients with diabetes, Wu et a $\tilde{l}$ comparing mild compression (18-25 mm $\mathrm{Hg}$ ) with no compression, have demonstrated the clinical advantage of compression therapy in terms of decreased edema and increased patient satisfaction. In patients with PAD, Midttun et $a l^{t}$ investigated the effect of compression therapy on the systolic toe blood pressure, which was not significantly influenced by compression therapy. Furthermore, they reported visual edema reduction as well as general improvement in patients' well-being. In summary, the current literature regarding compression therapy in patients with diabetes or PAD mostly reports positive results; therefore, compression therapy is widely recommended. However, the whole field of compression therapy reveals a huge lack of empirical data 
and measurements within patients at risk. One particular aspect is the microcirculation, which is compromised by interstitial edema; this may lead to tissue malnutrition. On the other hand, the compression therapy itself may hypothetically cause reduced tissue perfusion, especially in patients with PAD and diabetes. ${ }^{67}$

This study aims to analyze the influence of medical compression therapy on microcirculation in patients with PAD or diabetes mellitus.

\section{MATERIALS AND METHODS}

Patients

A prospective analysis of 94 consecutive patients undergoing medical compression therapy was performed (67 men, 27 women). The study cohort consisted of 44 patients with diabetes mellitus, 45 patients with PAD and 5 healthy controls. The data were prospectively collected between May 2018 and February 2019. Prior to enrollment, a feasibility study (pilot phase) was realized (five patients with diabetes, five patients with PAD and five healthy controls). Informed consent was obtained from all patients.

\section{Study design}

The present analysis was designed as a two-armed study. The first arm (PAD arm) included patients with PAD and no diabetes, and the second arm (diabetes arm) included patients with diabetes without PAD.

The inclusion/exclusion criteria were as follows:

- Inclusion criteria for PAD arm:

- Symptomatic claudication (Rutherford stage 1-3).

- Leg edema.

- No palpable foot pulses.

- Ankle brachial index (ABI) $<0.9$ and $>0.6$.

- Ankle absolute pressure $>60 \mathrm{~mm} \mathrm{Hg}$.

- Absence of diabetes mellitus (type 1 and 2).

- Exclusion criteria for PAD arm:

- Rutherford stages 0 and 4-6.

- Absence of leg edema.

- Palpable foot pulses.

- $\mathrm{ABI}>0.9$ and $<0.6$.

- Ankle absolute pressure $<60 \mathrm{~mm} \mathrm{Hg}$.

- Coexisting diabetes mellitus (type 1 and 2).

- Inclusion criteria for diabetes arm:

- Diabetes mellitus type 2 (history of more than 2 years with at least one antidiabetic medication; either insulin-dependent or not).

- Leg edema.

- Palpable foot pulses.

- Pallesthesia score $>6$.

- University of Texas Wound Classification System grade $0 .^{8}$

- Exclusion criteria for diabetes arm:

- Absence of diabetes mellitus type 2, history of less than 2 years of diabetes, dietetic treatment of diabetes mellitus.

- Absence of leg edema.
- No palpable foot pulses.

- Pallesthesia score $<6$.

- University of Texas Wound Classification System grade $>0 .{ }^{8}$

Each patient received medical compression therapy of one leg with two different compression classes (compression class I (CCLI), 18-21 mm Hg; and compression class II (CCLII), $23-32 \mathrm{~mm} \mathrm{Hg}$ ) for at least 3 hours. In this study the mediven angio medical compression stocking classes I and II were used (medi, Bayreuth, Germany).

Microperfusion before, during and after the compression therapy was measured by a combined method of laser Doppler flowmetry and white light tissue spectrometry (O2C, Oxygen to See; LEA Medizintechnik, Giessen, Germany; see also the "Technical aspects of O2C' section). For measurements the probes were positioned below the compression stockings. Different areas of interest were defined to measure microcirculation. For the most distal perfusion zone, the great toe (M1) was assessed, in addition to the lateral ankle (M2) as the location with the highest compression pressure, and the dorsum of the calf (M3). Investigations were conducted in four different positions. For the first investigation, the patient was placed in supine position (Sup). Afterwards, the leg was positioned at a $65 \mathrm{~cm}$ elevation (Up), leading to a decrease in hydrostatic pressure and therefore to a reduced perfusion pressure of the foot. ${ }^{9}$ The third investigation was performed in a seated position (Sit), followed by the fourth investigation in an upright position (Stand). The assessments were performed at five different time points. First, a baseline measurement of each patient without stockings was conducted (Base). The second measurement was performed directly after dressing of the stocking (CCLI), and the third measurement was conducted after a 3-hour wearing time of CCLI, while the patient was still wearing the stocking. The measurement procedure was then repeated with CCLII compression stockings (see figure 1A).

Additionally, the wearing comfort of the medical compression stockings was evaluated using a Likerttype scale (scale 1-10, with 1 indicating optimal wearing comfort and 10 massive impairment).

\section{Technical aspects of $02 \mathrm{C}$}

The 'Oxygen-to-see' (or O2C) is a combined method of laser Doppler flowmetry and tissue spectrometry for measurement of tissue microperfusion using the following parameters: oxygen saturation of hemoglobin $\left(\mathrm{sO}_{2}\right.$, in \%), relative hemoglobin amount $(\mathrm{rHb}$, in arbitrary units (AU)), relative blood flow (AU) and blood flow velocity (AU). ${ }^{10-14}$ The method has been validated and normal values have been defined before. ${ }^{10} 13$ The O2C uses a white light of 500-630 nm wavelength as well as a laser light of $830 \mathrm{~nm}$ wavelength. A laser Doppler shift is caused by the movement of the erythrocytes, which is then detected by the device as blood velocity. The amount of erythrocytes in the analyzed volume, indirectly detected by the absorption of the hemoglobin, 
A
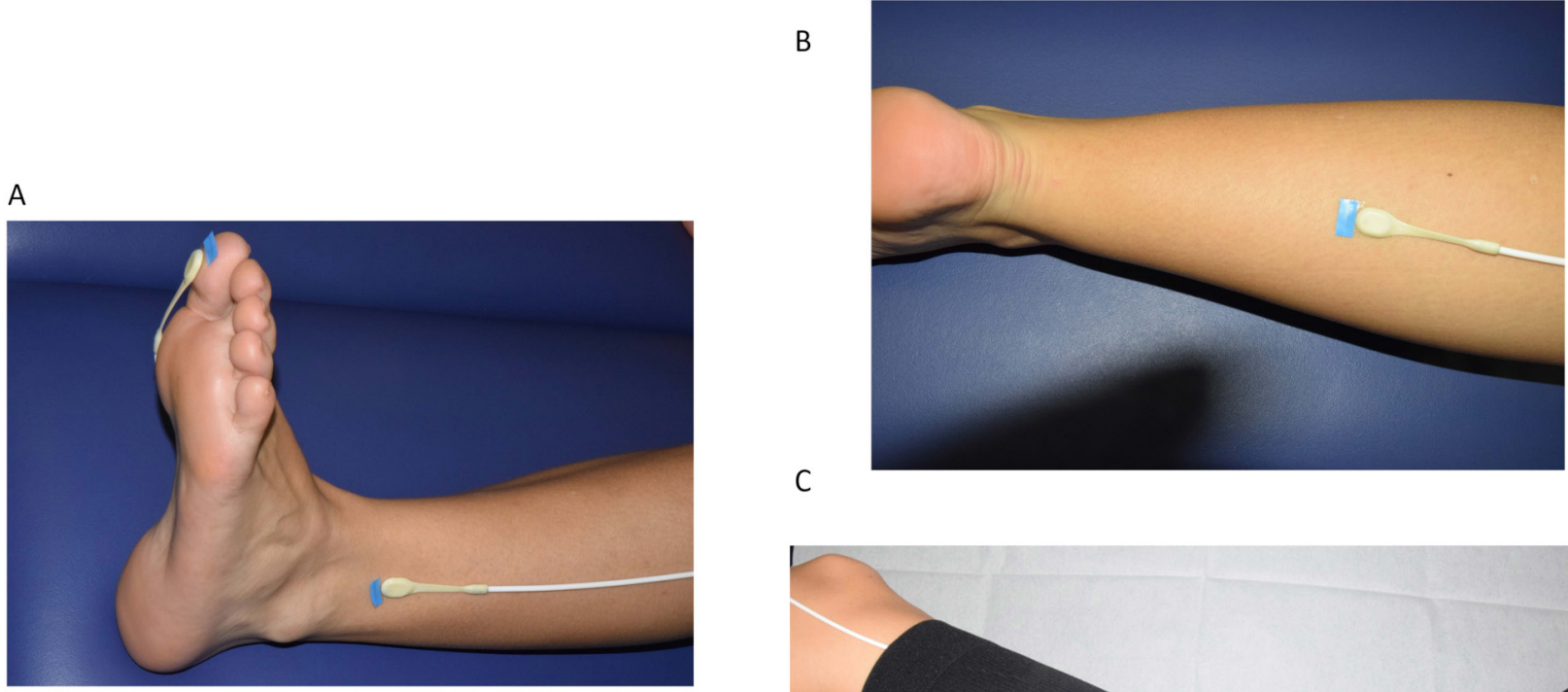

C

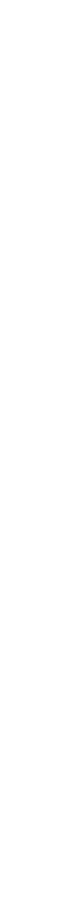

Figure 1 Positioning of the probes on the great toe (M1), lateral ankle (M2), and the calf (M3) without compression stocking (A and $\mathrm{B})$ and with the mediven angio medical compression stocking $(\mathrm{C})$.

yields the overall flow combined with the velocity value. Emitted white light registers the $\mathrm{sO}_{2}$ and $\mathrm{rHb} . \mathrm{sO}_{2}$ is determined by the color of the blood. The absorption of the white light in the tissue provides indication of the $\mathrm{rHb}$ parameter.

Velocity is enclosed in the parameter flow. Therefore, measurements concerning the safety of compression stockings subsequently focused on the $\mathrm{sO}_{2}$ and flow parameters.

The O2C is available for different types of probes. ${ }^{15}$ In this study, we made use of four probes of the LFx81.

\section{Statistical analysis}

In order to evaluate the impact of the compression stockings on microperfusion, effect estimates with corresponding $95 \%$ CI for the mean differences of $\mathrm{sO}_{2} /$ flow under CCLI/CCLII compared with each baseline measurement have been computed using the $\mathrm{R}$ Base function t-test.

In addition, regression analysis was performed in order to quantify the impact of leg position and probe localization on microperfusion. A linear mixed regression model has been computed for each combination of disease (diabetes vs PAD), compression classes (CCLI vs CCLII) and marker $\left(\mathrm{sO}_{2}\right.$ vs flow), resulting in eight separate models. The models included random intercepts and the baseline measurement of the corresponding microperfusion in order to account for correlations within the single patients as well as the different potentials of change depending on the varying baseline values. Models were computed using the function lme() from the R package nlme. All analyses were carried out with the R V.3.6.1 programming language.

\section{RESULTS}

\section{Feasibility study (pilot phase)}

The first 15 patients were included during the pilot phase. The sample was divided into five healthy controls, five patients with diabetes and five patients with PAD. During this study period, the safety aspect as well as feasibility were assessed. Concerning the safety analysis, none of the included subjects showed any skin induration or allergic reactions as to the compression stockings or the positioned probes after a total wearing time of 6 hours. The flat probes of the O2C device could be positioned at the different locations (M1-M3) below the medical compression stockings and were well tolerated by the participants. Additionally, the results of the perfusion measurements showed a dependence on the different measuring positions (healthy controls; see online supplementary figure $1 \mathrm{~A}-\mathrm{C}$ ). According to these results, a total of 44 patients with diabetes mellitus and 45 patients with PAD were included. Patients' characteristics are shown in table 1.

\section{Clinical trial}

Patients with diabetes mellitus

Perfusion assessments were conducted at the time points base, CCLI and CCLII. 


\begin{tabular}{|c|c|c|}
\hline & PAD (n) & $\begin{array}{l}\text { Diabetes } \\
\text { mellitus (n) }\end{array}$ \\
\hline Number of patients & 45 & 44 \\
\hline $\begin{array}{l}\text { Age, years, mean } \\
\text { (minimum-maximum) }\end{array}$ & $68.8(53-81)$ & $66.1(18-82)$ \\
\hline Sex (male; female) & $30 ; 15$ & $35 ; 9$ \\
\hline Hypertension & 41 & 37 \\
\hline Hypercholesterolemia & 25 & 31 \\
\hline Myocardial insufficiency & 1 & 0 \\
\hline Renal insufficiency & 1 & 4 \\
\hline $\begin{array}{l}\text { Ankle brachial index, median } \\
\text { (minimum-maximum) }\end{array}$ & $0.75(0.6-0.85)$ & $1.0(0.95-1.2)^{*}$ \\
\hline
\end{tabular}

${ }^{*}$ Falsely elevated $\mathrm{ABI}$ because mediasclerosis was excluded from the calculation.

$\mathrm{ABI}$, ankle brachial index; PAD, peripheral arterial disease.

\section{Sitting position}

For the Sit position, no significant changes in the mean values for the $\mathrm{sO}_{2}$ and flow parameters in the $\mathrm{M} 1$ location as well as for the flow parameter in the M2 location were seen under compression therapy $\left(\mathrm{sO}_{2} \mathrm{M} 1\right.$ : CCLI: $\mathrm{p}=$ not significant (n.s.), CCLII: $\mathrm{p}=$ n.s.; flow M1: CCLI: $\mathrm{p}=\mathrm{n} . \mathrm{s}$. , CCLII: $p=n . s .$, M2: CCLI: $p=n s$, CCLII: $p=n . s$.$) . However,$ interestingly, the $\mathrm{sO}_{2}$ yielded a significant improvement in the $\mathrm{M} 2$ location in both compression classes $\left(\mathrm{sO}_{2} \mathrm{M} 2\right.$ : CCLI: $\mathrm{p}=0.04$, CCLII: $\mathrm{p}<0.001$; see figure 2A).

\section{Standing position}

Similar results were recognized for the Stand position. The mean values did not change significantly for both perfusion parameters as well as for both locations under CCLI and CCLII compression $\left(\mathrm{sO}_{2} \mathrm{M} 1\right.$ : CCLI: $\mathrm{p}=0.06$, CCLII: $p=n . s .$, M2: CCLI: $p=n . s .$, CCLII: $p=0.11$; flow M1: CCLI: $p=n . s .$, CCLII: $p=$ n.s., M2: CCLI: $p=n . s .$, CCLII: $\mathrm{p}=$ n.s.; see figure $2 \mathrm{~B}$ ).

\section{Elevated position}

The elevation (Up position) seemed to have a relevant influence on the perfusion parameters. Both perfusion parameters on both positions showed a decrease in the mean values under compression therapy, in some cases significant $\left(\mathrm{sO}_{2} \mathrm{M} 1\right.$ : CCLI: $\mathrm{p}<0.001$, CCLII: $\mathrm{p}=$ n.s., $\mathrm{M} 2$ : CCLI: $\mathrm{p}=$ n.s., CCLII: $\mathrm{p}=0.01$; flow M1: CCLI: $\mathrm{p}=0.01$, CCLII: $\mathrm{p}=$ n.s., M2: CCLI: $\mathrm{p}=0.08$, CCLII: $\mathrm{p}=$ n.s.; see figure $2 \mathrm{C}$ ).

\section{Patients with PAD \\ Sitting position}

In the Sit position, the mean values for the $\mathrm{sO}_{2}$ and flow parameters showed no significant changes at the M1 location under compression therapy $\left(\mathrm{sO}_{2} \mathrm{M} 1\right.$ : CCLI: $\mathrm{p}=\mathrm{n} . \mathrm{s}$., CCLII: $p=n . s . ;$ flow M1: CCLI: $p=n . s .$, CCLII: $p=n . s . ;$ see figure 3). However, at the M2 location, flow showed significant improvement under both compression classes as well as $\mathrm{sO}_{2}$ under CCLI compression $\left(\mathrm{sO}_{2}\right.$ M2: CCLI: $\mathrm{p}=0.03$, CCLII: $\mathrm{p}=0.06$; flow M2: CCLI: $\mathrm{p}=0.01$, CCLII: $\mathrm{p}<0.01$; see figure $3 \mathrm{~A}$ ).

\section{Standing position}

Assessment in the Stand position showed similar results. The mean values for $\mathrm{sO}_{2}$ and flow at the M1 location showed a tendency toward worsening perfusion $\left(\mathrm{sO}_{2}\right.$ M1: CCLI: $p=n . s .$, CCLII: $p=0.02$; flow M1: CCLI: $p=n . s$. ,
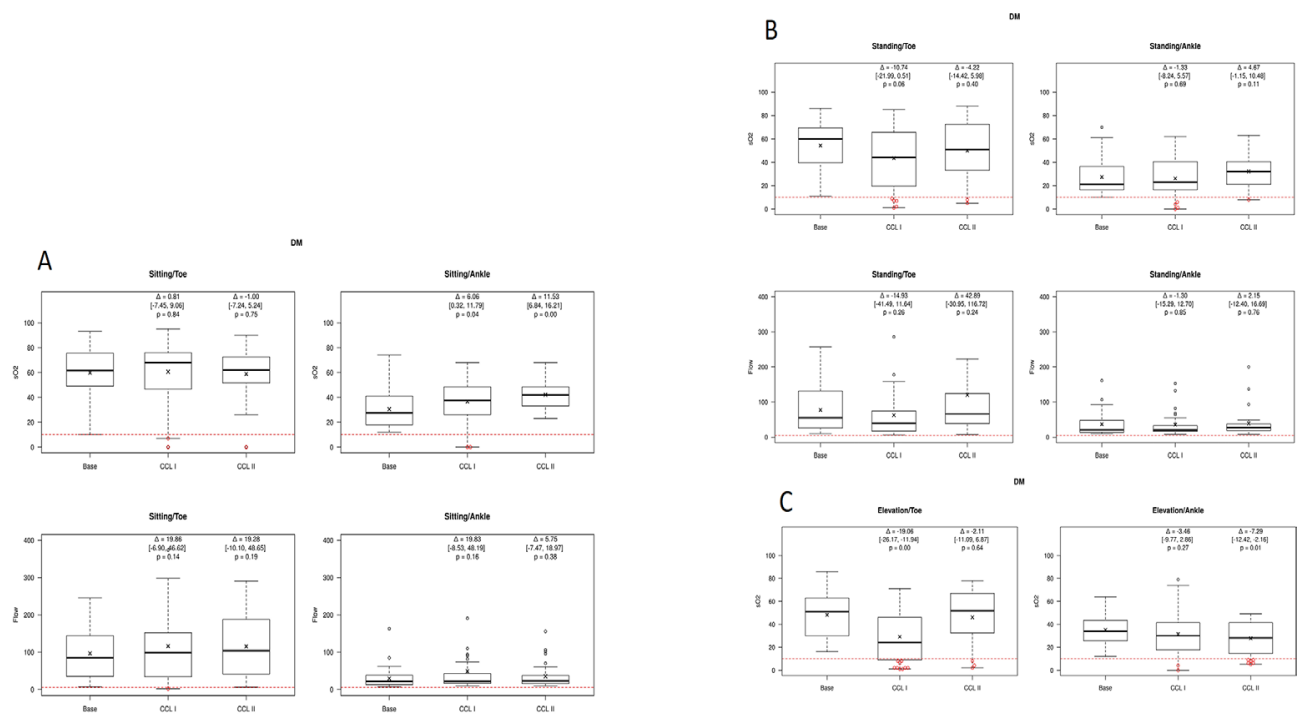

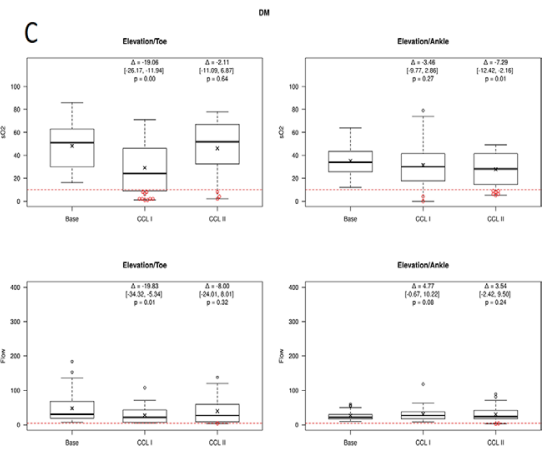

Figure 2 Results of the perfusion assessments in patients with diabetes in the sitting (A), standing (B) and elevated (C) positions. Measurements were performed on the great toe and the lateral ankle under compression therapy (classes I and II). CCLI, compression class I; CCLII, compression class II; DM, diabetes mellitus; $\mathrm{sO}_{2}$, oxygen saturation of hemoglobin. 

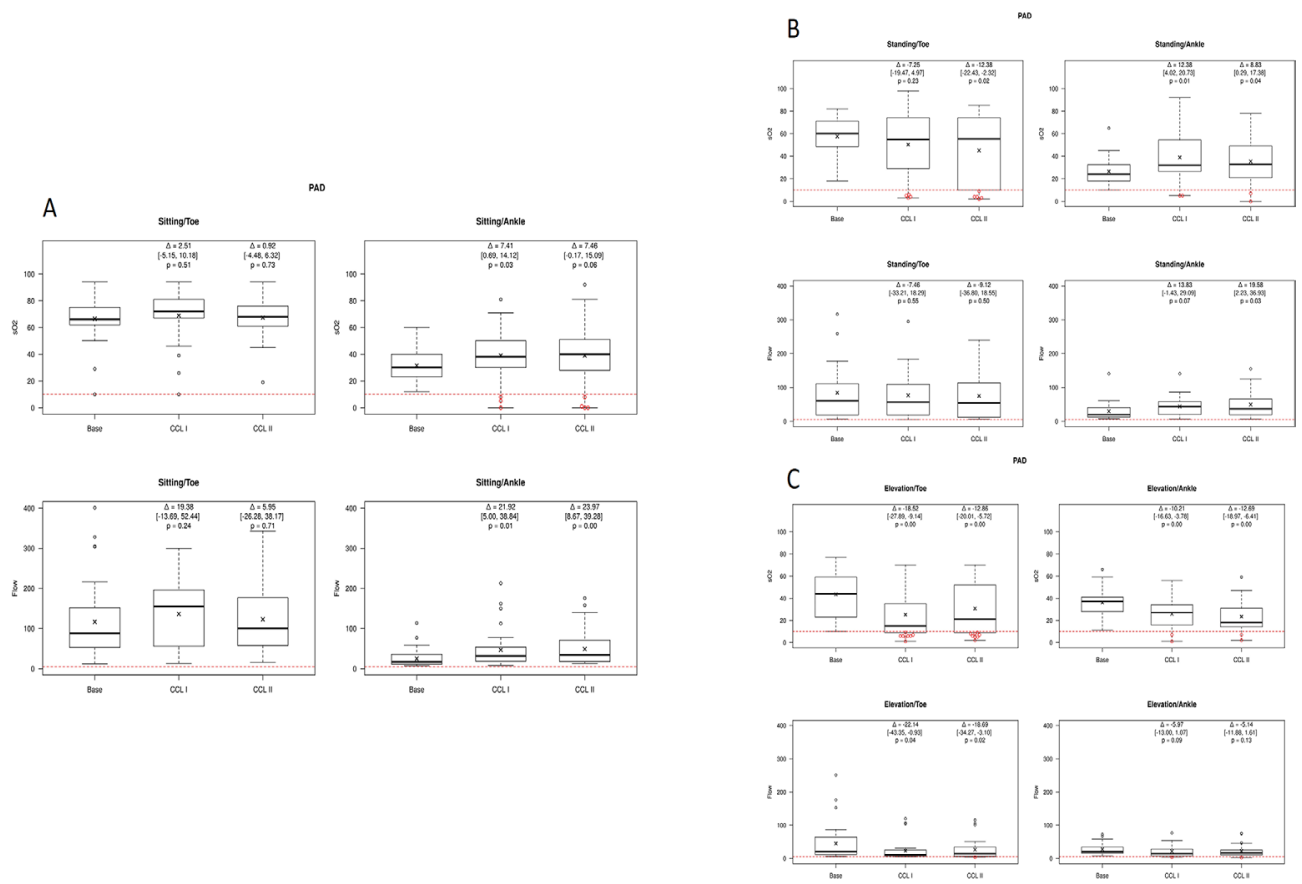

Figure 3 Results of the perfusion assessments in patients with PAD in the sitting (A), standing (B) and elevated (C) positions. Measurements were performed on the great toe and the lateral ankle under compression therapy (classes I and II). CCLI, compression class I; CCLII, compression class II; PAD, peripheral arterial disease; $\mathrm{sO}_{2}$, oxygen saturation of hemoglobi

CCLII: p=n.s.; see figure 3). In contrast, at the M2 location a significant improvement in $\mathrm{sO}_{2}$ was seen under CCLI and CCLII compression as well as for the flow parameter under CCLII compression $\mathrm{sO}_{2}$ M2: CCLI: $\mathrm{p}=0.01$, CCLII: $\mathrm{p}=0.04$; flow M2: CCLI: $\mathrm{p}=0.07$, CCLII: $\mathrm{p}=0.03$; see figure $3 \mathrm{~B}$ ).

\section{Elevated position}

Similar to the results in patients with diabetes, elevation seems to have the most influence on perfusion under compression therapy. In both localizations (M1 and M2) as well as for both compression classes, the mean values decreased $\left(\mathrm{sO}_{2} \mathrm{M} 1\right.$ : CCLI: $\mathrm{p}<0.001$, CCLII: $\mathrm{p}<0.001$; $\mathrm{M} 2$ : CCLI: $p<0.001$, CCLII: $p<0.001$; flow M1: CCLI: $p=0.04$, CCLII: $p=0.02$; M2: CCLI: $p=0.09$, CCLII: $p=n . s . ;$ see figure $3 \mathrm{C})$.

\section{Influence of position and localization on microperfusion}

Further regression analysis was conducted to assess the influence of the leg position and the probe localization on microcirculation under compression therapy. All results were correlated to the reference position Sit/ M2.

The results indicate that there is a similar influence of leg position on elevation (Up) for both groups (diabetes and $\mathrm{PAD}$ ). Elevation as well as the standing position were found to have a negative influence on microcirculation under compression therapy. In this study cohort, the localization of the probes under compression therapy was associated with less influence on microperfusion (see table 2).

\section{Clinical results}

No study-related adverse events occurred during the entire study. In none of the patients relevant skin lesions, abrasions, or pressure-related skin damages were seen. The overall wearing comfort was good, with a mean of 1.84 (SD 0.84) for medical compression stockings class I and a mean of 2.10 (STD 0.92) for medical compression stockings class II (on a scale of $1-10$, with 1 indicating optimal wearing comfort and 10 massive impairment).

\section{DISCUSSION}

The application of compression stockings in varying compression classes in patients with either PAD or diabetes mellitus has been widely discussed in the literature. Different efforts have been made to answer this question, including assessment of macrocirculation, by defining certain ABI as cut-off parameters; this is however subject to several parameters of influence. ${ }^{1451617}$ This study aimed to gain further insights into the direct effects of compression therapy on skin microcirculation.

By evaluation of the different means of microcirculation parameters $\left(\mathrm{sO}_{2}\right.$ and flow) in different locations and positions (Sit/Stand, diabetes and PAD group) under compression therapy (classes I and II), no significant reduction in microperfusion could be observed. On the contrary, definite locations and positions may even account for an improvement in perfusion. Abu-Own et $a l^{18}$ who investigated the influence of pressure on skin microcirculation, showed similar results. They found an increase in the microcirculatory flow velocity up to a certain level of pressure. However, in our study, in both 
Table 2 Results of the regression analysis assessing the influence of leg position as well as probe localization on microcirculation under compression therapy

\begin{tabular}{|c|c|c|c|c|}
\hline & \multicolumn{2}{|l|}{$\mathrm{sO}_{2}$} & \multicolumn{2}{|l|}{ Flow } \\
\hline & CCLI & CCLII & CCLI & CCLII \\
\hline \multicolumn{5}{|l|}{ Diabetes mellitus } \\
\hline Baseline & $\begin{array}{l}0.497^{\star \star \star} \\
(0.383,0.611)\end{array}$ & $\begin{array}{l}0.295^{\star \star \star} \\
(0.189,0.400)\end{array}$ & $\begin{array}{l}0.583^{\star * \star} \\
(0.435,0.731)\end{array}$ & $\begin{array}{l}0.778^{\star \star \star} \\
(0.572,0.984)\end{array}$ \\
\hline Elevation & $\begin{array}{l}-17.546^{\star \star \star} \\
(-23.119,-11.973)\end{array}$ & $\begin{array}{l}-13.961^{\star \star \star} \\
(-19.053,-8.870)\end{array}$ & $\begin{array}{l}-41.754^{\star \star \star} \\
(-57.781,-25.728)\end{array}$ & $\begin{array}{l}-22.119^{\star} \\
(-45.058,0.821)\end{array}$ \\
\hline Standing & $\begin{array}{l}-10.434^{\star \star \star} \\
(-16.115,-4.752)\end{array}$ & $\begin{array}{l}-6.493^{\star \star \star} \\
(-11.692,-1.295)\end{array}$ & $\begin{array}{l}-31.253^{\star \star \star} \\
(-46.931,-15.575)\end{array}$ & $\begin{array}{l}1.102 \\
(-21.400,23.603)\end{array}$ \\
\hline Toe & $\begin{array}{l}0.819 \\
(-4.207,5.845)\end{array}$ & $\begin{array}{l}9.164^{\star \star \star} \\
(4.561,13.767)\end{array}$ & $\begin{array}{l}9.683 \\
(-4.081,23.447)\end{array}$ & $\begin{array}{l}21.367^{\star *} \\
(1.794,40.940)\end{array}$ \\
\hline Intercept & $\begin{array}{l}26.859^{\star \star \star} \\
(20.705,33.013)\end{array}$ & $\begin{array}{l}33.064^{\star \star \star} \\
(27.312,38.816)\end{array}$ & $\begin{array}{l}44.410^{\star \star \star} \\
(29.794,59.026)\end{array}$ & $\begin{array}{l}19.232^{\star} \\
(-1.436,39.899)\end{array}$ \\
\hline Observations & 255 & 257 & 263 & 263 \\
\hline \multicolumn{5}{|c|}{ Peripheral arterial disease } \\
\hline Baseline & $\begin{array}{l}0.346^{\star \star \star} \\
(0.229,0.463)\end{array}$ & $\begin{array}{l}0.461^{\star \star \star} \\
(0.349,0.573)\end{array}$ & $\begin{array}{l}0.481^{\star \star \star} \\
(0.375,0.587)\end{array}$ & $\begin{array}{l}0.511^{* \star *} \\
(0.410,0.611)\end{array}$ \\
\hline Elevation & $\begin{array}{l}-26.205^{\star \star \star} \\
(-32.217,-20.193)\end{array}$ & $\begin{array}{l}-21.155^{\star \star \star} \\
(-27.033,-15.277)\end{array}$ & $\begin{array}{l}-50.650^{\star \star \star} \\
(-64.974,-36.325)\end{array}$ & $\begin{array}{l}-43.930^{\star \star \star} \\
(-57.465 \\
-30.395)\end{array}$ \\
\hline Standing & $\begin{array}{l}-12.359^{\star \star \star} \\
(18.408,-6.310)\end{array}$ & $\begin{array}{l}-9.494^{\star \star \star} \\
(-15.412,-3.576)\end{array}$ & $\begin{array}{l}-25.690^{\star * \star} \\
(-39.646,-11.734)\end{array}$ & $\begin{array}{l}-17.737^{\star * \star} \\
(-30.928,-4.546)\end{array}$ \\
\hline Toe & $\begin{array}{l}3.963 \\
(-1.280,9.206)\end{array}$ & $\begin{array}{l}4.266 \\
(-0.850,9.383)\end{array}$ & $\begin{array}{l}9.483 \\
(-2.720,21.686)\end{array}$ & $\begin{array}{l}7.353 \\
(-4.188,18.893)\end{array}$ \\
\hline Intercept & $\begin{array}{l}34.792^{\star \star \star} \\
(28.165,41.419)\end{array}$ & $\begin{array}{l}27.765^{\star \star \star} \\
(21.421,34.110)\end{array}$ & $\begin{array}{l}50.806^{\star \star \star} \\
(37.726,63.885)\end{array}$ & $\begin{array}{l}45.853^{\star \star \star} \\
(33.494,58.211)\end{array}$ \\
\hline Observations & 257 & 257 & 262 & 263 \\
\hline
\end{tabular}

All results were correlated to the reference position Sit/M2.

${ }^{*} \mathrm{P}<0.1,{ }^{\star \star} \mathrm{P}<0.05,{ }^{\star \star *} \mathrm{P}<0.01$.

CCLI, compression class I; CCLII, compression class II; $\mathrm{sO}_{2}$, oxygen saturation of hemoglobin.

patient groups, a strong dependency on the different measuring positions was recognized. This is demonstrated in the elevated position (Up). Here we observed a decrease in microperfusion parameters in some patients even beyond the critical values $\left(\mathrm{sO}_{2}<10 \%\right.$; flow $\left.<5 \mathrm{AU}\right)$. However, comparison of the diabetes and PAD groups with the healthy group (pilot phase, five healthy volunteers) yielded similar results. A decrease in microperfusion during elevation procedure was also detected in those participants without vascular disease or diabetes (see online supplementary figure 1 ). In the regression analysis, the elevated position was found to have the strongest influence on perfusion under compression therapy. Considering this, one reason might be the summation of the pressures interfering with the perfusion. By elevating the legs to a height of $65 \mathrm{~cm}$, the hydrostatic pressure decrease accounts for about $50 \mathrm{~mm} \mathrm{Hg}$, leading in summation with the compression stockings (classes I and II) to theoretical absolute pressures between 68 and $82 \mathrm{~mm} \mathrm{Hg}$. These additional forces face the physiologic foot perfusion pressure, which might compromise foot microperfusion even in healthy subjects. Against this background, a permanent $65 \mathrm{~cm}$ leg elevation cannot be considered as a physiologic position. Similar results have been shown by Park et al ${ }^{19}$ who investigated microperfusion in patients with diabetes using the transcutaneous oxygen tension method. Here, foot elevation of $24 \mathrm{~cm}$ caused an overall decrease in the partial pressure of oxygen parameters of $26.8 \%$, even without compression therapy.

Further influence on microperfusion was seen in the standing position. When compared with the sitting position, the upright standing position in general seems to have a negative influence on microcirculation. A possible explanation might be the reduced venous backflow, which in comparison with other body positions leads to venous stasis, and thus negatively affects microperfusion. However, we observed that, in some cases, the perfusion actually improved under compression therapy in the standing position (mainly in the M2 location), obviously by promoting the venous backflow through external compression.

Different studies aimed on evaluation of compression therapy on skin microcirculation. ${ }^{18}{ }^{20-24}$ Most of them found no compromising influence on perfusion up to 
certain levels of pressure. Nevertheless, these analyses at hand might contribute to clarifying the role of compression therapy in patients with PAD and diabetes with concomitant leg edema due to chronic venous disease or lymphatic stasis.

One of the few studies investigating the influence of compression stockings on patients with diabetes mellitus was published by Wu et al. ${ }^{16}$ They performed an assessment of compression therapy as to ABI, toe brachial index (TBI) and skin perfusion pressure at 4-week follow-up. Although the circulation parameters were not measured during compression, the compression stockings did not influence the lower extremity perfusion in terms of ABI, TBI and skin perfusion pressure, similar to the results presented here. Other findings, published by Midttun et at $t^{t}$ showed similar results by assessment of the systolic great toe blood pressure and blood flow measured by a heat-washout method. However, unlike in the present study, these assessments were not conducted under direct compression therapy. Couzan $e t a l^{17}$ assessed the influence of progressive elastic compression on the arterial circulation by measuring the ABI and TBI at 15-day follow-up. This group could not detect any compromising influence of the compression therapy on the arterial circulation as well.

Concerning patients with diabetes, Wu et a $\tilde{l}^{\tilde{p}}$ investigated the effect of mild compression $(18-25 \mathrm{~mm} \mathrm{Hg}$ ) on lower extremity edema and the circulation at 4-week follow-up. No skin lesions or ulcerations were found. Furthermore, an improvement in ABI during the study period was observed, most likely caused by a reduced leg edema leading to an improved arterial circulation.

There are some limitations to this study. First, long-term follow-up was not investigated; however, as the primary aim was the direct evaluation of microperfusion during compression therapy, this was outside the topic of the present analysis.

Second, the probes of the O2C device were positioned below the compression stockings. At these locations, a slightly elevated compression pressure may lead to further reduction of the skin perfusion. Although the probes are very thin $(1.5 \mathrm{~mm})$, this confounding factor cannot be excluded in total. This should be analyzed in further studies.

However, keeping in mind these limitations, this study is the first which directly investigates the influence of compression stockings on skin microcirculation in patients with diabetes and PAD. The present results could not demonstrate a relevant negative influence of compression therapy on skin microcirculation neither in patient cohorts at risk nor in healthy controls.

\section{CONCLUSION}

In consideration of the study inclusion criteria, use of compression stockings is safe and feasible in patients with diabetes and PAD. We did not find relevant impairment of microperfusion parameters under compression therapy in these patient subgroups in physiologic body positions during the study period. Foot elevation of $65 \mathrm{~cm}$ leads to significant decrease in microcirculation in both study arms as well as in the healthy control group. Presuming close medical supervision, patient cohorts at risk due to PAD or diabetes mellitus suffering from leg edema can benefit from compression therapy. This treatment was confirmed as safe in application and was also well tolerated by the patients. However, these results need to be confirmed by long-term tolerance data.

Contributors UR, AM: conceived the design of the study, execution of the investigations, writing of the paper. WL: conceived the design of the study, writing of the paper. AG: execution of the investigations. VA-S: execution of the investigations. CG: statistical analysis.

Funding The authors received funding from medi, Bayreuth, Germany.

Competing interests None declared.

Patient consent for publication Not required.

Ethics approval The study was conducted in congruence with the Declaration of Helsinki and was approved by the local ethics committee of the Friedrich-Alexander University Erlangen-Nuernberg (265_17B).

Provenance and peer review Not commissioned; externally peer reviewed.

Data availability statement Data are deidentified participant data and are available upon reasonable request. Contact details: Ulrich.rother@uk-erlangen.de.

Open access This is an open access article distributed in accordance with the Creative Commons Attribution Non Commercial (CC BY-NC 4.0) license, which permits others to distribute, remix, adapt, build upon this work non-commercially, and license their derivative works on different terms, provided the original work is properly cited, appropriate credit is given, any changes made indicated, and the use is non-commercial. See: http://creativecommons.org/licenses/by-nc/4.0/.

ORCID iD

Ulrich Rother http://orcid.org/0000-0002-4016-5673

\section{REFERENCES}

1 Humphreys ML, Stewart AHR, Gohel MS, et al. Management of mixed arterial and venous leg ulcers. Br J Surg 2007;94:1104-7.

2 Borland C, Amadi A, Murphy P, et al. Biochemical and clinical correlates of diuretic therapy in the elderly. Age Ageing 1986;15:357-63.

3 O'Meara S, Cullum NA, Nelson EA. Compression for venous leg ulcers. Cochrane Database Syst Rev 2009:CD000265.

4 Midttun M, Ahmadzay NF, Henriksen JH. Does comprilan bandage have any influence on peripheral perfusion in patients with oedema? Clin Physiol Funct Imaging 2010;30:323-7.

5 Wu SC, Crews RT, Najafi B, et al. Safety and efficacy of mild compression (18-25 $\mathrm{mm} \mathrm{Hg}$ ) therapy in patients with diabetes and lower extremity edema. J Diabetes Sci Technol 2012;6:641-7.

6 Eneroth M, Persson BM. Amputation for occlusive arterial disease. A prospective multicentre study of 177 amputees. Int Orthop 1992;16:383-7.

7 Pawlaczyk K, Gabriel M, Urbanek T, et al. Effects of intermittent pneumatic compression on reduction of postoperative lower extremity edema and normalization of foot microcirculation flow in patients undergoing arterial revascularization. Med Sci Monit 2015;21:3986-92.

8 Lavery LA, Armstrong DG, Harkless LB. Classification of diabetic foot wounds. J Foot Ankle Surg 1996;35:528-31.

9 Rother U, Kapust J, Lang W, et al. The Angiosome concept evaluated on the basis of Microperfusion in critical limb ischemia Patients-an oxygen to see guided study. Microcirculation 2015;22:737-43.

10 Beckert S, Witte MB, Königsrainer A, et al. The impact of the microlightguide $\mathrm{O} 2 \mathrm{C}$ for the quantification of tissue ischemia in diabetic foot ulcers. Diabetes Care 2004;27:2863-7.

11 Beier JP, Horch RE, Arkudas A, et al. Decision-making in DIEP and ms-TRAM flaps: the potential role for a combined laser Doppler spectrophotometry system. J Plast Reconstr Aesthet Surg 2013;66:73-9. 
12 Fechner G, von Pezold J, Luzar O, et al. Modified spectrometry (O2C device) of intraoperative microperfusion predicts organ function after kidney transplantation: a pilot study. Transplant Proc 2009;41:3575-9.

13 Forst T, Hohberg C, Tarakci E, et al. Reliability of lightguide spectrophotometry $(\mathrm{O} 2 \mathrm{C})$ for the investigation of skin tissue microvascular blood flow and tissue oxygen supply in diabetic and nondiabetic subjects. J Diabetes Sci Technol 2008;2:1151-6.

14 Walter B, Bauer R, Krug A, et al. Simultaneous measurement of local cortical blood flow and tissue oxygen saturation by near infra-red laser Doppler flowmetry and remission spectroscopy in the pig brain. Acta Neurochir Suppl 2002;81:197-9.

15 Jakobsson A, Nilsson GE. Prediction of sampling depth and photon pathlength in laser Doppler flowmetry. Med Biol Eng Comput 1993;31:301-7.

16 Wu SC, Crews RT, Skratsky M, et al. Control of lower extremity edema in patients with diabetes: double blind randomized controlled trial assessing the efficacy of mild compression diabetic socks. Diabetes Res Clin Pract 2017;127:35-43.

17 Couzan S, Pouget J-F, Le Hello C, et al. High tolerance of progressive elastic compression in peripheral arterial disease. Vasa 2019;48:413-7.
18 Abu-Own A, Shami SK, Chittenden SJ, et al. Microangiopathy of the skin and the effect of leg compression in patients with chronic venous insufficiency. J Vasc Surg 1994;19:1074-83.

19 Park DJ, Han SK, Kim WK. Is the foot elevation the optimal position for wound healing of a diabetic foot? J Plast Reconstr Aesthet Surg 2010;63:561-4.

20 Abu-Own A, Cheatle T, Scurr JH, et al. Effects of intermittent pneumatic compression of the foot on the microcirculatory function in arterial disease. Eur J Vasc Surg 1993;7:488-92.

21 Own AA, Scurr JH, Coleridge-Smith PD. [Effects of compression stockings on cutaneous microcirculation]. Phlebologie 1993;46:671-2.

22 Mosti G, labichella ML, Partsch H. Compression therapy in mixed ulcers increases venous output and arterial perfusion. J Vasc Surg 2012;55:122-8

23 Stansal A, Tella E, Yannoutsos A, et al. Supervised shortstretch compression therapy in mixed leg ulcers. J Med Vasc 2018;43:225-30.

24 Top S, Arveschoug AK, Fogh K. Do short-stretch bandages affect distal blood pressure in patients with mixed aetiology leg ulcers? J Wound Care 2009;18:439-42. 